\title{
Chi trả các dịch vụ môi trường ở Việt Nam Từ chính sách tới thực tiễn
}

Phạm Thu Thủy', Karen Bennett², Vũ Tấn Phương³, Jake Brunner, Lê Ngọc Dũng', Nguyễn Đình Tiến ${ }^{5}$

\section{GIỚI THIÊUU TỔNG QUAN}

Nguyên tắc cơ bản của Chi trả dịch vụ môi trường (PES) là đảm bảo lợi ích cho người cung cấp dịch vụ môi trường, ở cả cấp độ cá nhân và cộng đồng, thông qua việc nhận được bồi hoàn cho chi phí của việc cung cấp những dịch vụ này. Theo Wunder (2005), PES được hiểu là "một thỏa thuận cung cấp một dịch vụ môi trường đã được xác định cụ thể giữa ít nhất một người mua dịch vụ và một người cung cấp dịch vụ. Thỏa thuận này mang tính tự nguyện giữa hai bên và người cung cấp dịch vụ sẽ chỉ nhận được tiền khi cung cấp dịch vụ môi trường một cách liên tục (tính điều kiện)". Từ năm 2004, Chính phủ Việt Nam đã thiết lập cơ sở pháp lý nhằm thực hiện chương trình quốc gia về chi trả dịch vụ môi trường rừng (PFES) thông qua Luật Bảo vệ và Phát triển rừng sửa đổi (2004). Năm 2008, Quyết định số 380/QĐ-TTg của Thủ tướng Chính phủ đã cho phép thí điểm chính sách chi trả dịch vụ môi trường rừng tại tỉnh Sơn La và Lâm Đồng. Năm 2010, Nghị định số 99 đã được ban hành nhằm triển khai Chính sách chi trả dịch vụ môi trường rừng trên phạm vi toàn quốc từ 1/1/2011. Có thể nói,Việt Nam đã trở thành quốc gia đầu tiên tại châu Á ban hành và triển khai chính sách PFES ở cấp quốc gia.

Mục tiêu của PFES tại Việt Nam là: bảo vệ diện tích rừng hiện có, nâng cao chất lượng rừng, gia tăng đóng góp của ngành lâm nghiệp vào nề kinh tế quốc dân, giảm nhẹ gánh nặng lên ngân sách Nhà nước cho việc đầu tư vào bảo vệ và phát triển rừng, và đảm bảo an sinh xã hội của người làm nghề rừng. Tuy nhiên, đến nay vẫn chưa có một đánh giá và nghiên cứu toàn diện về thực trạng triển khai PFES ở Việt Nam.
Tóm lược chính sách này cung cấp cho các nhà hoạch định chính sách những đánh giá và phân tích cụ thể về tính hiệu quả, hiệu ích và công bằng của PFES trong quá trình triển khai từ năm 2008. Chúng tôi tập trung nghiên cứu trên ba khía cạnh của PFES: (1) xây dựng các cơ sở pháp lý (các quy định pháp lý và cơ cấu tổ chức thực hiện), (2) cơ chế chia sẻ lợi î́ch (phân bổ tiền chi trả và sự tham gia của các bên), và (3) giám sát và đánh giá (giám sát các dịch vụ môi trường, hợp đồng, dòng tiền và tác động xã hội từ PFES). Nghiên cứu đã thu thập và phân tích các tài liệu cả trong nước và quốc tế có liên quan để hiểu rõ cơ sở pháp lý, thực trạng triển khai PFES tại Việt Nam và rút ra các bài học kinh nghiệm. Chúng tôi đã thực hiện hơn hai trăm (210) cuộc phỏng vấn bán cấu trúc với đại diện của các bên liên quan từ trung ương đến địa phương, các tổ chức nghiên cứu, nhà tài trợ, tổ chức phi chính phủ, tổ chức xã hội dân sự, người cung cấp dịch vụ và người mua dịch vụ, đồng thời chúng tôi cũng tiến hành các nghiên cứu điểm tại các tỉnh Bắc Kạn, Sơn La, Hòa Bình, Nha Trang, Nam Định, Thừa Thiên Huế, Quảng Nam, Đắk Nông và Lâm Đồng để đánh giá thực trạng triển khai và đưa ra các bài học quan trọng. Bên cạnh đó, hai hội thảo chuyên đề đã được tổ chức để tham vấn với các chuyên gia, nhà hoạch định chính sách, và các nhà quản lý về các kết quả và phát hiện nêu trong nghiên cứu này.
Tổ chức Nghiên cứu Lâm nghiệp Quốc tế (CIFOR)
Cơ quan Lâm nghiệp Hoa Kỳ (US Forest Service)
Viện Khoa học Lâm Nghiệp Việt Nam (VAFS)
Liên minh bảo tồn thiên nhiên quốc tế (IUCN)
Trường Đại Học Nông Nghiệp Hà Nội (HAU) 


\section{CÁC PHÁT HIỆN CHÍNH}

\subsection{Các thành tựu chính của PFES tại Viêt Nam từ năm 2008 - 2012}

Nghiên cứu chỉ ra rằng PFES nhận được sự quan tâm và hỗ trợ to lớn từ Chính phủ và các bộ, ngành. Tổng cộng có 20 văn bản pháp lý đã được ban hành dưới dạng Nghị định, Quyết định của Thủ tướng và Thông tư, Quyết định của Bộ Nông nghiệp và Phát triển Nông thôn, tạo nên một cơ sở pháp lý quan trọng cho việc triển khai Chính sách chi trả dịch vụ môi trường rừng. Trong các dịch vụ môi trường đã được quy định, dịch vụ phòng hộ đầu nguồn (bảo vệ đất, hạn chế xói mòn và bồi lắng lòng hồ, lòng sông, lòng suối; điều tiết và duy trì nguôn nước cho sản xuất và xã hội) đã có nhiều thành tựu quan trọng, đồng thời đưa ra các bài học kinh nghiệm cho việc hoàn thiện cơ cấu thực hiện PFES. Hiện nay, việc triển khai PFES chủ yếu dựa vào Quỹ bảo vệ và Phát triển rừng được thành lập ở cấp trung ương và cấp tỉnh. Tính tới tháng 12/2012, có 35 tỉnh trong tổng số 63 tỉnh thành trên cả nước đã thành lập Ban chỉ đạo về triển khai Nghị định 05/NE-CP và Nghị định 99/NE-CP; có 27 tỉnh trong 35 tỉnh này đã thành lập và vận hành Quỹ Bảo vệ và Phát triển rừng cấp tỉnh. Với sự hỗ trợ của Chính phủ, việc triển khai PFES (từ 2008 đến 2012) đã tao điều kiện cho việc nâng cao năng lực cho các cơ quan quản lý, nâng cao nhận thức xã hội và thu được 1.782 tỉ đồng (khoảng 85 triệu USD), trong đó tiền chi trả từ các cơ sở sản xuất thủy điện chiếm khoảng 98\%, từ các công ty cung cấp nước là $2 \%$ và từ các công ty kinh doanh dịch vụ du lịch, lữ hành là $0.1 \%$. Tổng nguồn thu từ chi trả dịch vụ môi trường rừng ước tính chiếm 0.8\% ngân sách đầu tư lâm nghiệp.

\subsection{Các phát hiện chính về thể chế và cơ sở pháp lý}

\subsubsection{Khung pháp lý chung về thực hiện PFES đã được} xây dựng

Từ năm 2008, khung pháp lý quốc gia về PFES, gồm các cơ sở pháp lý, cơ cấu tổ chức, quản lý tài chính và các hợp đông ủy thác đã được quy định tại hơn 20 văn bản pháp quy ở các cấp khác nhau (4 văn bản pháp quy dưới dạng Nghị định và Quyết định của Thủ tướng, 16 văn bản pháp quy dưới dạng Quyết định và Thông tư của Bộ Nông nghiệp và Phát triển Nông thôn). Trong số các văn bản ban hành, có 5 văn bản pháp quy cung cấp hướng dẫn pháp lý về việc thành lập, tổ chức và quản lý Quỹ Bảo vệ và Phát triển rừng ở cấp tỉnh và trung ương, 11 văn bản hướng dẫn chung về tổ chức thực hiện PFES.
Cơ chế vận hành PFES tại Việt Nam chủ yếu dựa vào Quỹ Bảo vệ và Phát triển rừng cấp trung ương và cấp tỉnh. Các Quỹ sẽ ký hợp đồng với người mua dịch vụ và thu tiền từ các dịch vụ được cung cấp; chuẩn bị kế hoạch chi trả; giám sát và phân bổ tiền tới người cung cấp dịch vụ; chuẩn bị và đệ trình các báo cáo theo từng giai đoạn tới Quỹ Bảo vệ và Phát triển rừng trung ương. Người cung cấp dịch vụ là các cá nhân, hộ gia đình, cộng đồng và tổ chức được xem xét bởi các Quỹ cấp tỉnh dựa trên chứng nhận quyền sử dụng đất. Người sử dụng dịch vụ được quy định tại Nghị định 99 là các công ty cung cấp nước, các cơ sở sản xuất thủy điện và công ty kinh doanh du lịch. Tuy nhiên, thực chất số tiền chi trả dịch vụ môi trường rừng được chuyển cho người sử dụng dịch vụ cuối cùng là người dân và các đối tượng sử dụng điện và nước (số tiền này được hạch toán trong giá bán điện và nước).

\subsubsection{Trong các dịch vụ môi trường rừng quy định tại Nghị định 99 thì chỉ có 2 dịch vụ được thực hiện do thiếu các cơ sở pháp lý và các hướng dẫn chi tiết}

Nghị định 99 quy định các loại dịch vụ môi trường phải chi trả, gôm:

(i) Phòng hộ đầu nguồn (gồm bảo vệ đất, hạn chế xói mòn, bôii lắng lòng hồ, lòng sông, lòng suối; điều tiết và duy trì nguồn nước cho hoạt động sản xuất và đời sống xã hội)

(ii) Bảo vệ cảnh quan tự nhiên và bảo tồn đa dạng sinh học của các hệ sinh thái rừng phục vụ cho du lịch

(iii) Hấp thụ và lưu giữ các bon của rừng, giảm phát thải gây hiệu ứng nhà kính bằng các biện pháp ngăn chặn suy thoái và giảm diện tích rừng và phát triển rừng bền vững ;

(iv) Dịch vụ cung ứng bãi đẻ, nguồn thức ăn và con giống tự nhiên và nguồn nước từ rừng cho các hoạt động nuôi trồng thủy sản.

Tới nay, Bộ Nông nghiệp và Phát triển Nông thôn, cơ quan chịu trách nhiệm về tổ chức triển khai PFES, đã ban hành các quy định và hướng dẫn khá chi tiết về triển khai hai loại dịch vụ đầu tiên (phòng hộ đầu nguồn và dịch vụ du lịch sinh thái). Mức chi trả dịch vụ môi trường rừng là mức chi trả cố định áp dụng cho người sử dụng dịch vụ. Đối với các cơ sở sản xuất thủy điện, mức chi trả là 20 VND/Kwh điện thương phẩm, $40 \mathrm{VND} / \mathrm{m}^{3}$ nước sạch đối với các công ty cấp nước và các công ty du lịch chi trả hàng năm từ 1-2\% tổng doanh thu. Số tiền chi trả cho 1 ha rừng cho người cung cấp dịch vụ được xác định dựa trên tổng số tiền thu sau khi trừ đi chi phí quản lý (10\%) và quỹ dự phòng (5\%) chia cho tổng diện tích rừng có cung ứng dịch vụ môi trường rừng. 
Mặc dù loại dịch vụ thứ hai (vẻ đẹp cảnh quan và bảo tồn đa dạng sinh học) đã được triển khai ở một mức độ nhất định, sự đa dạng của các bên liên quan, nhiều mô hình cơ chế hoạt động và mối quan hệ phức tạp giữa Người cung cấp dịch vụ -Trung gian - Người mua và sử dụng dịch vụ làm cho việc triển khai trở nên khó khăn và gặp nhiều mâu thuẫn. Tới nay, có nhiều khó khăn trong việc thực hiện dịch vụ này đã được phát hiện, bao gồm:

- Người sử dụng dịch vụ không hiểu rõ vẻ đẹp cảnh quan đóng góp như thế nào cho công việc kinh doanh của họ;

- Những người sử dụng dịch vụ khác nhau có sự sẵn sàng chi trả khác nhau dựa trên số doanh thu của họ (doanh thu càng cao thì mức độ sẵn sàng chi trả càng cao);

- Thiếu quy định rõ ràng về nhóm nào trong hoạt động kinh doanh du lịch nên chi trả. Việc thu tiền dịch vụ môi trường từ một số công ty thương mại du lịch rất khó khăn (ví dụ, các công ty có thể vận động hành lang chính quyền địa phương để bỏ qua việc chi trả), và thiếu minh bạch (ví dụ, sổ sách tài chính không rõ ràng, khó khăn trong việc tiếp cận thông tin về doanh thu của các công ty lớn và thiếu sổ sách tài chính của các cơ sở kinh doanh nhỏ như cơ sở cung cấp dịch vụ lưu trú tại nhà);

- Có những sự khác biệt đáng kể trong việc tính toán số tiên chi trả (ví dụ, dựa theo phí vào cổng và dựa theo doanh thu); và

- Các bên thực hiện đều chưa rõ sẽ đánh giá và giám sát dịch vụ vẻ đẹp cảnh quan dựa trên tiêu chí nào.

Mặc dù có khá nhiều hoạt động thí điểm được hỗ trợ bởi các nhà tài trợ cho loại dịch vụ thứ ba "hấp thụ carbon" (ví dụ, Lâm Đồng và Nghệ An) và dịch vụ thứ tư "cung cấp dịch vụ bãi đẻ, con giống tự nhiên, nguồn thức ăn và nguồn nước từ rừng cho nuôi trồng thủy sản" (ví dụ, Vườn quốc gia Xuân Thủy, tỉnh Bến Tre và Cà Mau), nhưng hầu hết các hoạt động thí điểm này vẫn đang trong giai đoạn thực hiện và các kết quả đầu ra chưa được tổng hợp. Vi vậy, Bộ Nông nghiệp và Phát triển Nông thôn đã đề nghị Thủ tướng Chính phủ tiếp tục tiến hành các hoạt động thí điểm này thêm 2-3 năm và tổng kết các bài học trước khi ban hành khung pháp lý và các hướng dẫn cho cơ chế PES đối với các dịch vụ này.

Đối với dịch vụ hấp thu carbon của rừng, Chính phủ đã phê duyệt Chương trình hành động Quốc gia về Giảm phát thải khí nhà kính thông qua nỗ lực hạn chế mất rừng và suy thoái rừng, quản lý bền vững tài nguyên rừng, bảo tồn và nâng cao trữ lượng các bon rừng (REDD+) như là nền tảng cho việc giảm phát thải khí nhà kính trong lâm nghiệp. Hơn nữa, với sự hỗ trợ từ UN-REDD, Việt Nam đã hoàn thành pha 1 cho việc thiết lập sự sẵn sàng cho thực hiện REDD+ và đang chuẩn bị thực hiện pha 2 nhằm triển khai thí điểm các hoạt động REDD+ (2013-2016). Trong các hoạt động thí điểm này, các tiêu chí và cơ chế chi trả cho dịch vụ hấp thụ carbon đã và đang được kiểm nghiệm. Khung pháp lý cho loại dịch vụ này sẽ được ban hành dựa trên các kết quả từ Chương trình thí điểm UN-REDD pha 2. Hiện nay, Bộ Nông nghiệp và Phát triển Nông thôn vẫn chưa quyết định nên tổ chức như thế nào để kết hợp PFES và REDD+ và đánh giá cơ chế thích hợp cho việc triển khai dịch vụ hấp thụ carbon. Đối với dịch vụ cung cấp bãi đẻ và các dịch vụ cho nuôi trồng thủy sản, Bộ Nông nghiệp và Phát triển Nông thôn, với sự hỗ trợ từ GIZ, IUCN, CIFOR, đã phát triển một số lựa chọn chính sách, trong đó việc tính phí chi trả có thể dựa trên doanh thu, lợi nhuận, diện tích rừng, lượng nước sử dụng, hoặc áp dụng phí chi trả cố định cũng như tiềm năng áp dụng việc tính phí dựa trên chứng chỉ, các lựa chọn chính sách hiện đang được thảo luận và chờ đợi kết quả.

\subsubsection{Tî lệ giải ngân tiền chi trả dịch vụ môi trường thấp}

Việc giải ngân từ Quỹ Bảo vệ và Phát triển rừng tới những người cung cấp dịch vụ môi trường là khá thấp, với tỉ lệ giải ngân chung chỉ đạt 46\% tổng số tiền thu được tới nay. Tỉ lệ giải ngân tiền PFES thấp là do công tác kiểm kê rừng chưa hoàn thiện, sự chậm chạp trong việc giao đất, giao rừng, số lượng lớn người cung cấp dịch vụ sống rải rác tại các khu vực hẻo lánh, năng lực kỹ thuật và tài chính hạn chế ở cả cấp trung ương và địa phương, và sự phối hợp chưa chặt chẽ giữa các cơ quan. Uu tiên trước mắt là cần phải nâng cao chất lượng các báo cáo kỹ thuật để thu thập và cập nhật diện tích rừng, chất lượng rừng và tình trạng pháp lý của việc quản lý rừng phải được ưu tiên xem xét để triển khai PFES một cách hiệu quả và hiệu ích tại Việt Nam. Thêm vào đó,cần phải nâng cao nhận thức và xây dựng năng lực cho các bên có liên quan để họ hiểu biết về lợi ích của việc bảo vệ rừng và nhận thức những giá trị tiềm năng của tiền chi trả PFES tới việc phát triển kinh tế xã hội. Cuối cùng, các hướng dẫn bổ sung về việc sử dụng số tiền PFES không được phân bổ và sự giám sát nội bộ hoặc giám sát của bên thứ ba về các giao dịch tài chính có thể có tác động tích cực đến quá trình thanh toán tiền chi trả dịch vụ môi trường rừng. 


\subsubsection{Chi phí giao dịch cao}

Chi phí giao dịch bị đå̉y lên cao là do số lượng lớn các chủ rừng (các chủ rừng là cá nhân, hộ gia đình), thủ tục hành chính phức tạp, năng lực hạn chế của cán bộ thực hiện, các mâu thuẫn lợi ích và việc chia sẻ thông tin và hợp tác chưa chặt chẽ giữa các cơ quan liên quan. Để giảm chi phí giao dịch, việc nhóm các hộ chủ rừng riêng rẽ thành nhóm ở một mức độ phù hợp theo từng khu vực địa lý có thể có tác dụng làm giảm chi phí đáng kể. Việc áp dụng phương pháp thanh toán tiền chi trả dịch vụ môi trường thông qua ngân hàng (ví dụ Ngân hàng Chính sách Xã hội) đã được thực hiện ở Sơn La, tuy nhiên do sự phân bổ rải rác của những người cung cấp dịch vụ, dẫn đến việc các cán bộ ngân hàng đi tới địa bàn không thường xuyên cộng với mức chi trả thấpnên phương pháp tiếp cận này đã không chứng minh được sự hiệu quả. Ngược lại, ở những địa bàn có mật độ dân số cao, việc chi trả qua ngân hàng và sử dụng công nghệ từ điện thoại di động nên được xem xét và áp dụng.

\subsubsection{Sự chưa rõ ràng về tư cách pháp nhân của cộng đồng để tham gia vào những thỏa thuận về PFES làm giảm sự quan tâm của các cộng đồng địa phương tới việc bảo vệ và phát triển rừng}

Hiện nay theo Nghị định 99, người cung cấp dịch vụ bao gồm cá nhân, hộ gia đình, cộng đồng, các tổ chức Nhà nước và các công ty tư nhân hiện đang giữ quyền sử dụng đất. Lâm nghiệp cộng đồng được xem như một mô hình thành công trong việc bảo vệ và phát triển rừng và hiện nay (ví dụ, Sơn La). Mặc dù tư cách pháp lý của cộng đồng được công nhận trong Luật Bảo vệ và Phát triển Rừng năm 2004 với nhiệm vụ bảo vệ và quản lý rừng, tuy nhiên cộng đồng lại không được xem là có tư cách pháp nhân để tham gia vào các hợp đồng dân sự trong Luật Dân sự 2005. Điều này làm giảm sự quan tâm của cộng đông địa phương tới việc quản bảo vệ và phát triển rừng. Mô hình cộng đồng được đăng ký như "Hợp tác xã lâm nghiệp" tại điểm nghiên cứu tại Thái Nguyên là một trong những giải pháp tiềm năng để khắc phục hạn chế này.

\subsubsection{Trong một số trường hợp, người sử dụng dịch vụ và người cung cấp dịch vụ môi trường rừng chưa được xác định rô ràng}

Việc xác định người mua và người cung cấp dịch vụ môi trường rừng trong bối cảnh PFES chưa được rõ ràng. Người mua dịch vụ, được xác định là các công ty cung cấp nước và cơ sở sản xuất thủy điện trong Nghị định 99, trên thực tế chỉ đóng vai trò trung gian bởi tiền chi trả dịch vụ môi trường được chuyển tới người tiêu dùng cuối cùng là nhân dân. Người dân và đối tượng sử dụng điện và nước là người mua dịch vụ môi trường thực sự và hiện tại họ chưa nhận thức được vấn đề này.Công ty cung cấp nước và cơ sở sản xuất thủy điện nhận được lợi ích từ việc bảo vệ rừng và các dịch vụ môi trường ở vùng đầu nguồn, đặc biệt là dịch vụ chống bồi lắng lòng hồ, do vậy họ cũng nên chi trả cho những dịch vụ môi trường này như một phần chi phí kinh doanh. Để nâng cao hiệu quả của PFES, cần nâng cao nhận thức và hiểu biết của người sử dụng và mua dịch vụ về giá trị của PFES tới sức khỏe và phúc lợi của con người và thúc đẩy sự tham gia của người sử dụng dịch vụ để phát triển chính sách PFES một cách toàn diện.

Ở nhiều điểm nghiên cứu (ví dụ, các vườn quốc gia cung cấp vẻ đẹp cảnh quan và bảo tồn đa dạng sinh học), tình trạng người mua và sử dụng dịch vụ cũng đồng thời là người cung cấp làm phức tạp thêm việc thiết kế cơ chế PFES. GIZ (2012) và các công ty du lịch tại Lâm Đồng chỉ ra vai trò không rõ ràng của các khu bảo tôn và vườn quốc gia trong quá trình chi trả. Từ góc độ pháp lý, họ có thể có các vai trò khác nhau tùy thuộc vào việc thiết lập cơ chế PFES. Theo quy định về chủ quản lý rừng, vườn quốc gia và khu bảo tồn và các cơ quan lâm nghiệp được xem như một kiểu nhà cung cấp dịch vụ môi trường và vì vậy, có đủ điều kiện để nhận tiền chi trả PFES.Tuy nhiên, các đối tượng này cũng đồng thời tổ chức kinh doanh và có lợi nhuận từ các hoạt động kinh doanh du lịch của họ và do đó họ cũng là người sử dụng dịch vụ môi trường.Thêm vào đó, họ thường ký hợp đồng khoán bảo vệ rừng với các hộ dân, họ cũng được xem như là bên trung gian trong việc điều phối tiền chi trả PFES tới những người bảo vệ rừng.Vai trò trung gian này sẽ cho phép các đối tượng trên có quyền giữ 10\% chi phí quản lý trong cơ chế PFES. Vi vậy, điêu quan trọng là cần cân đối giữa lợi nhuận thu được bởi các vườn quốc gia và khu bảo tồn dựa trên các dịch vụ họ kinh doanh và số tiền họ được nhận dựa trên tư cách là bên cung cấp dịch vụ môi trường.

Việc trao đổi thông tin giữa người cung cấp dịch vụ, người mua và sử dụng dịch vụ và bên trung gian phải được thực hiện thường xuyên để đảm bảo tính minh bạch trong hệ thống chi trả.Việc phát triển hệ thống chia sẻ thông tin là cần thiết để kết nối người cung cấp dịch vụ và những người hưởng lợi để đảm bảo sự tham gia toàn diện của cộng đồng vào PFES. 


\subsubsection{Những người sử dụng dịch vụ là khối tư nhân có những bất lợi nếu so sánh với người sử dụng dịch vụ là công ty Nhà nước}

Khi Nghị định 99 được thông qua vào năm 2010, các cơ sở sản xuất thủy điện tư nhân bị ràng buộc bởi một hợp đồng cung cấp điện với Tổng công ty điện lực Việt Nam với một mức giá cung cấp điện cố định. Vi vậy, họ không được phép chuyển tiền chi trả PFES tới người tiêu dùng cuối cùng như các công ty Nhà nước.Thông qua các kênh và diễn đàn khác nhau, vấn đề này đã được giải quyết vào năm 2012.Tuy nhiên, một vấn đề chưa được làm rõ là liệu các cơ sở sản xuất thủy điện tư nhân này sẽ được hoàn lại số tiền PFES mà họ đã chi trả cho giai đoạn 2010 - 2011 không? Tương tự, nhiều công ty cung cấp nước và công ty du lịch không thể chuyển khoản phí chi trả tới người tiêu dùng cuối cùng. Việc này dẫn đến việc chia sẻ chi phí không công bằng giữa các công ty khác nhau và cần phải có sự linh hoạt trong hệ thống để đảm bảo tính ràng buộc của người sử dụng dịch vụ môi trường.

\subsubsection{Liệu cơ chế PFES tại Việt Nam có phải là một cơ chế PES thực sự và vấn đề này quan trọng đến đâu?}

Nhiều học giả lập luận rằng các cơ chế PFES tại Việt Nam có sự khác biệt với định nghĩa quốc tế PES (Wunder 2005) bởi vì mức chi trả PES được thiết lập bởi Chính phủ chứ không phải là một giao dịch tự nguyện giữa người cung cấp dịch vụ và người sử dụng dịch vụ, và đang hoạt động hiệu quả dưới dạng thuế hoặc phí sử dụng điện và nước. Tuy nhiên, chúng tôi lập luận rằng điều quan trọng không phải là PFES có thực sự là PES hay không mà chúng ta nên tập trung vào xem xét liệu các chính sách PFES hiện hành có được thực hiện một cách hiệu quả, hiệu ích, công bằng hay chưa.

\subsection{Các phát hiện chính về việc chia sẻ lợi ích}

\subsubsection{Mức chi trả thấp đối lập với Chi phí cơ hội cao}

Cơ chế PFES đối với dịch vụ phòng hộ đầu nguồn (chống xói mòn, bồi lắng; điều tiết và duy trì nguồn nước) tiếp tục bị đe dọa bởi chi phí cơ hội cao cho việc chuyển đổi mục đích sử dụng đất. Mức chi trả PFES hiện tại là quá thấp để bồi hoàn những lợi ích kinh tế bị mất đi từ việc chuyển đổi rừng, đặc biệt là việc chuyển đổi sang trồng ngô hoặc cà phê hoặc chuyển đổi rừng ngập mặn thành đầm nuôi tôm. Tuy nhiên, PFES không phải là một liều thuốc trị bách bệnh. Có thể đề xuất việc kết hợp PFES với các chương trình lâm nghiệp và phát triển kinh tế khác để đa dạng hóa nguôn lực tài chính. Kết hợp việc chi trả PFES trực tiếp với các lợi ích gián tiếp khác như là nâng cao giáo dục và xây dựng năng lực cho cộng đồng hoặc tham gia cùng các chương trình có những tác động tiềm năng dài hạn để giảm nghèo có thể làm tăng sự sẵn sàng của cộng đồng vào việc tham gia các cam kết của chương trình PFES dẫu cho mức chi trả có thấp.

\subsection{2 Đánh đổi giữa tính hiệu quả, hiệu ích và công bằng}

Cơ chế chia sẻ lợi ích hiện tại không tính đến chất lượng rừng (hệ số K), mà đang được thực hiện để đáp ứng nguyện vọng và định nghĩa ở cấp độ địa phương về sự công bằng (ví dụ, tất cả người dân nên được chi trả một mức như nhau bất kể điều kiện kinh tế, xã hội, tư cách pháp lý của họ ra sao và hiện trạng của diện tích rừng họ được chi trả để bảo vệ). Tuy nhiên, cách tiếp cận này không tạo nên lợi ích cho việc nâng cao chất lượng công tác bảo vệ và phát triển rừng (không hiệu quả). Hơn nữa, do mỗi hộ dân chỉ quản lý một diện tích rừng khá nhỏ (ví dụ, Sơn La), dẫn đến tiền chi trả PFES rất thấp. Như đã đề cập ở trên, phương pháp chi trả theo nhóm có thể sẽ giải quyết được thực trạng này.

Mức chi trả PFES hiện được tính theo tổng nguồn thu từ người sử dụng dịch vụ (sau khi đã trừ đi quản lý phí và quỹ dự phòng) chia cho tổng diện tích rừng cung cấp dịch vụ môi trường rừng để có mức chi trả cho từng hecta. Điều này có thể dẫn đến lưu vực có tî lệ rừng che phủ cao sẽ nhận được mức chi trả cho từng hecta thấp hơn, và ngược lại lưu vực có tî lệ rừng che phủ thấp sẽ nhận được mức chi trả cho từng hecta cao hơn. Điêu này mang đến lợi ích cao hơn trong việc bảo vệ rừng ở những khu vực có tỷ lệ che phủ rừng ít hơn, do đó có thể tạo nên tác động tích cực nhưng cũng tạo nên nguy cơ cho việc chuyển đổi mục đích sử dụng đất tại các khu vực có độ che phủ rừng cao do mức chi trả thấp. Mặt khác, người sử dụng dịch vụ môi trường có khả năng không nhận được nhiêu giá trị từ PFES bởi vì họ vẫn phải chi trả một mức như nhau bất kể chất lượng dịch vụ môi trường tại các lưu vực. Mục đích của chương trình PFES là nhằm bảo vệ diện tích rừng hiện có và nếu chỉ phụ thuộc vào PFES thì sẽ không thể giải quyết được mọi vấn đề liên quan đến dịch vụ môi trường rừng.Tuy nhiên, việc kết hợp PFES với các chương trình bảo tôn khác sẽ nâng cao việc bảo vệ lưu vực một cách tổng quan. Một vài lựa chọn chính sách có thể được xem xét bao gồm:

- Đ Đánh giá lại cơ sở xác định mức chi trả mà người sử dụng dịch vụ phải trả bao gồm mức chi trả cố định hiện tại với một mức chi trả có thể điều chỉnh được dựa trên tỉ lệ doanh thu có được từ các dịch vụ tương tự như mức phí áp dụng với các công ty du lịch;

- Quyết định xem liệu mức chi trả có nên dựa theo tỉ lệ rừng tại lưu vực; 
- Tập trung nguồn lực tài chính của PFES tới các khu vực trọng điểm cung cấp những loại dịch vụ môi trường đặc biệt (ví dụ, diện tích rừng bên cạnh các sông suối nhận được mức chi trả cao hơn so với diện tích rừng xa sông suối hơn hoặc diện tích rừng với tiềm năng đa dạng sinh học cao nhận được mức chi trả cao hơn về vẻ đẹp cảnh quan và dịch vụ bảo tồn đa dạng sinh học hơn những diện tích rừng không cung cấp những dịch vụ này);

- Sử dụng một vài loại phí thu được, hoặc kết hợp PFES với các chương trình khác của Chính phủ để nâng cao cải thiện chức năng của lưu vực (ví dụ, phục hồi rừng hoặc sử dụng những mô hình quản lý đất và nước hiệu quả đối với các loại hình sử dụng đất khác để giảm xói mòn và bồi lắng);

\subsubsection{Thiếu các hướng dẫn cụ thể về việc sử dụng tiền chi trả từ PFES có thể dẫn tới việc sử dụng tiền PFES không đúng mục đích cấp độ thôn bản và cộng đồng}

Hiện đang có rất ít hướng dẫn về nguồn tiền thu từ PFES nên được sử dụng như thế nào và nghiên cứu chỉ ra rằng những người cung cấp dịch vụ hiện chưa được tham gia vào quá trình ra quyết định về việc sử dụng tiền thu từ PFES. Thiếu sự giám sát tạo ra nguy cơ sử dụng tiền chi trả không đúng mục đích. Mô hình về một quỹ ủy thác gồm nhiều bên tham gia với đại diện người sử dụng dịch vụ, người cung cấp dịch vụ, tổ chức phi chính phủ, tổ chức nghiên cứu và cơ quan chính phủ (ví dụ, tỉnh Hòa Bình) và mô hình hợp tác xã (tại Thái Nguyên) có được sự tin cậy từ cả người sử dụng dịch vụ và người cung cấp dịch vụ và nên được sử dụng như hình mẫu cho việc mở rộng PFES trên toàn quốc.Người cung cấp dịch vụ môi trường tại nhiều điểm nghiên cứu đều mong muốn nhận được lợi ích bằng cả hiện vật và lợi ích gián tiếp (ví dụ, tập huấn và xây dựng năng lực) và tiền mặt. Họ cũng nhận được hướng dẫn từ các cán bộ về việc làm sao để tối đa hóa hiệu quả từ tiền chi trả nhằm nâng cao điều kiện kinh tếxã hôi. Tuy nhiên, những hướng dẫn này phải có đủ sự linh hoạt để có được sự thích ứng cần thiết tại địa phương và phải sử dụng một cơ chế đưa ra quyết định có nhiều bên tham gia.

\subsection{Các phát hiện chính về hệ thống giám sát và đánh giá (M\&E) 2.4.1 Thiếu một hệ thống giám sát và đánh giá để định hướng tiến trình thực hiện PFES}

Hầu hết các hướng dẫn chính sách cho PFES đều tập trung vào cơ cấu tổ chức và hoạt động của Quỹ Bảo vệ và Phát triển rừng ở các cấp và hướng dẫn báo cáo tài chính mà chưa có hướng dẫn cụ thể về công tác giám sát và đánh giá. Việc chưa có các hướng dẫn cụ thể đã dẫn tới việc hiểu và thi hành khác nhau tại các địa phương và sự e dè trong triển khai do e ngại làm sai định hướng. Dựa theo khả năng tài chính và kỹ thuật ở các Quỹ cấp tỉnh, thiết kế cho hợp phần giám sát và đánh giá có thể sẽ tương đối đơn giản hoặc cũng có thể khá phức tạp. Đầu tiên, để bắt đầu triển khai PFES, việc giám sát phải đơn giản, tập trung vào các yếu tố đầu vào và việc tự đánh giá. Tuy nhiên, vào năm thứ 5, cần kỳ vọng rằng các nỗ lực giám sát phải được tài liệu hóa rõ ràng và đầy đủ để mô tả liệu quá trình có đạt được các mục tiêu môi trường, kinh tế, xã hội hay chưa? Một chương trình giám sát nên lồng ghép việc thành lập các điều kiện cơ sở, giám sát các yếu tố đầu vào của chương trình PFES và xác định đầu ra của PFES. Một hợp phần quan trọng của hệ thống giám sát và đánh giá là tiếp tục sử dụng, thông qua các diễn đàn đối thoại mở và phản hồi từ các bên liên quan, thông tin có được để cải tiến quá trình và nâng cao chính sách PFES và hệ thống cung cấp để đạt được những mục tiêu vọng.

\subsubsection{Chưa có các thông tin cơ sở về môi trường và điều kiện kinh tế xã hội}

Mặc dù đã có chương trình quốc gia về điều tra tài nguyên rừng, nhưng các cán bộ cấp tỉnh vẫn cho rằng dữ liệu này là không đầy đủ để xác định ranh giới diện tích rừng và chất lượng rừng tại cấp độ địa phương. Hiện đang thiếu sự rõ ràng về ranh giới diện tích rừng cho các chủ rừng trên bản đồ và ở thực địa. Việc sử dụng ảnh viễn thám và ảnh vệ tinh từ Google Earth hoặc các công nghệ khác có thể hỗ trợ rất nhiều cho việc thiết lập các thông tin và dữ liệu cơ sở. Những thông tin này là cốt lõi cho cả các chương trình khác đang được thiết lập tại Việt Nam, bao gồm cả REDD+, và các tổ chức nên làm việc với nhau để thiết lập dữ liệu cơ sở mà tất cả các bên liên quan có thể sử dụng nguồn thông tin đồng bộ nhằm đánh giá sự hiệu quả các chương trình của những tổ chức này.

Tương tự như vậy, các tổ chức khác nhau tham gia vào việc giám sát các yếu tố xã hội và kinh tế nên cùng hợp tác để thiết lập các thông tin cơ sở cho sự tham gia của cộng đồng vào chương trình PFES. Những đánh giá ban đầu có thể được sử dụng để kiểm nghiệm các lợi ích của chương trình PFES kể cả được phối hợp hoặc tách riêng với các chương trình khác. 


\subsubsection{Giám sát tính minh bạch của các hợp đồng trong PFES, dòng tiền và cơ chế phản hồi cần được thiết lập}

Nhận diện người sử dụng dịch vụ và người cung cấp dịch vụ, phát triển và giám sát hợp đồng và đảm bảo việc phân phối ngân sách hợp lý là rất quan trọng trong triển khai chương trình PFES. Mặc dù Nghị định 99 nhận diện được một số người sử dụng dịch vụ, tuy nhiên một số nhóm đối tượng sử dụng dịch vụ nhưng chưa được đề cập. Một kế hoạch chiến lược nhằm xác định rõ người sử dụng dịch vụ đích thực là rất quan trọng.

Việc tiến hành và thực hiện hợp đồng, đánh giá tính ràng buộc và tiến hành chi trả cho việc cung cấp các dịch vụ môi trường cần được tiến hành một cách minh bạch. Kiểm tra nội bộ hoặc giám sát bởi bên thứ ba hoặc các bên liên quan cần được xét kỹ càng hơn trong hệ thống giám sát và đánh giá. Hiện chưa có một hệ thống phản hồi hiệu quả và hệ thống phản hôii hiện nay chủ yếu thông qua trao đổi với trưởng thôn/bản bởi người dân không hiểu được hệ thống vận hành của PFES, không hiểu được quyền của họ, hoặc trong một số trường hợp họ không biết đọc, biết viết. Tuy nhiên tại nhiều điểm nghiên cứu đã cho thấy trưởng thôn/bản đã không thể đóng vai trò của một kênh phản hôi hiệu quả do lợi ích cá nhân của họ. Một quy trình giám sát và phản hồi ý kiến hiệu quả cần được thiết lập và giám sát để đảm bảo rằng những thắc mắc và nghi vấn của người dân được nhận diện và giải quyết kịp thời. Cuối cùng, sự chậm chạp trong quá trình kiểm chứng và phân bổ tiền chi trả dẫn tới sự thiếu tin tưởng của người dân, đồng thời dẫn tới việc sao nhãng khi thực hiện PFES. Một vài hạn chế trong việc thực hiện hợp đồng trong PFES được nhận diện như sau:

- Thiếu nguồn nhân lực và thiếu năng lực của cả chính quyền địa phương và cấp xã trong việc thực hiện và giám sát hợp đông PFES;

- Các hình phạt là quá nhẹ cho những hành vi sai phạm pháp luật;

- Thiếu sự đẩy mạnh tính ràng buộc (tiền vẫn được chi trả ngay cả khi có vi phạm luật);và

- Chưa có một hệ thống ghi nhận khiếu nại hoặc phản hồi.

Ngoài ta, giám sát thường dựa theo báo cáo của từng chủ rừng, do vậy những báo cáo này có thể mang tính chủ quan hoặc thiếu chính xác. Các hướng dẫn thi hành luật không rõ ràng làm ảnh hưởng tới sự sẵn sàng chi trả của người mua và sử dụng dịch vụ và do đó tác động xấu tới tính hiệu quả của PFES. Tất cả những vấn đề trên cần được nhận biết để nâng cao chất lượng đầu ra của PFES.

\subsubsection{Việc giám sát các kết quả đầu ra về môi trường và kinh tế xã hội của PFES cần được đẩy mạnh}

Mặc dù Nghị định 99 có quy định rằng mức chi trả PFES phải được dựa trên diện tích và chất lượng rừng, tuy nhiên trên thực tế, chủ yếu diện tích rừng được sử dụng để xác định mức chi trả cho tất cả các dịch vụ môi trường. Chủ rừng hiện tại đang tự báo cáo về hiện trạng rừng họ đang bảo vệ và khoảng $10 \%$ diện tích rừng của họ có thể được kiểm tra ngẫu nhiên bởi cán bộ kiểm lâm địa bàn nếu báo cáo đó bị nghi ngờ là không đáp ứng được yêu cầu. Hoạt động giám sát này thiếu đi sự minh bạch và các thông số định lượng để đảm bảo tính điều kiện hoặc việc cung cấp dịch vụ môi trường được thực sự diễn ra. Việc sử dụng công nghệ viễn thám kết hợp với việc kiểm chứng ngay tại địa bàn có thể mang đến sự đảm bảo chắc chắn hơn.

Nâng cao nhận thức của người dân về vai trò của rừng và bảo vệ rừng một cách có hiệu quả là nội dung được nhấn mạnh của PFES. Tuy nhiên, để nhận diện đầy đủ các kết quả đầu ra của các dịch vụ môi trường, cần có một chương trình và hệ thống đánh giá giám sát trên quy mô quốc gia. Việc kết hợp và hài hòa hóa PFES với các chương trình bảo tồn và phát triển kinh tế xã hội khác có thể sẽ tạo ra hiệu quả tốt hơn cho việc. Ví dụ, việc bảo vệ diện tích rừng hiện có không thể giải quyết hết các vấn đề về xói mòn và bồi lắng mà các cơ sở sản xuất thủy điện và công ty cung cấp nước đang phải gánh chịu. Xói mòn đất còn có nguyên nhân từ những loại hình sử dụng đất khác (ví dụ, canh tác nông nghiệp và xây dựng đường sá và cơ sở hạ tầng), những hoạt động vốn cung cấp lợi ích kinh tế - xã hội cho các cộng đồng ở những khu vực không có rừng trong cảnh quan chung. Do vậy, chính phủ cần quan tâm nhiều hơn đến các chương trình bảo tồn đất và nguồn nước ở cấp vĩ mô đồng thời tăng cường sự phối hợp giữa các bộ, ngành liên quan nhằm đảm bảo các chức năng phòng hộ đầu nguồn một cách hiệu quả.

Tác động xã hội của PFES là khá phức tạp và hiện thiếu các dữ liệu đáng tin cậy để chứng minh tác động tích cực của PFES tới nguồn thu nhập tại địa phương. Tiền chi trả PFES có thể là quá thấp và không đáng kể để nâng cao sinh kế tại địa phương và chi phí cơ hội là cao hơn khi so sánh với nguồn tiền chi trả này. Một chiến lược giám sát các tác động kinh tế xã hội với sự tham gia của các bên liên quan phải được thiết kế. 


\section{KẾT LUẬN}

Nghiên cứu nhấn mạnh rằng PFES được xem như một trong những điểm đột phá quan trọng trong ngành lâm nghiệp Việt Nam và chính sách này đang tiếp tục được hoàn thiện và cải tiến. Những thành tựu đáng kể về thiết lập khung pháp lý và tổ chức bộ máy, việc tạo ra nguồn thu đáng kể, đạt được các cam kết chính trị và sự quan tâm để hỗ trợ PFES ở cả cấp địa phương và cấp tỉnh cũng như ngay trong cộng đồng người dân địa phương hứa hẹn một tương lai tươi sáng cho PFES. Để nâng cao sự hiệu quả, hiệu ích và công bằng cho các kết quả đầu ra của PFES, các nhà hoạch định chính sách nên đảm bảo việc phân bổ tiền được minh bạch và được giải trình từ cấp trung ương tới địa phương thông qua việc phát triển một hệ thống giám sát và đánh giá với một cơ chế ghi nhận và phản hồi ý kiến rõ ràng. PFES cũng cần được hỗ trợ và kết hợp với các chương trình bảo tôn đất, nguồn nước ở lưu vực và phát triển kinh tế xã hội khác để mang đến một chương trình toàn diện hơn. Tổ chức thực hiện PFES cần phải tiến hành cùng với việc xây dựng năng lực dài hạn cho các cán bộ Nhà nước, các hộ gia đình, cộng đồng và người đại diện của các bên liên quan.

\section{Lời cảm ơn}

Chúng tôi xin chân thành cảm ơn sự hỗ trợ quý báu của Cơ quan Phát triển Quốc tế Hoa Kỳ, Cơ quan Lâm nghiệp Hoa Kỳ, Cơ quan hợp tác phát triển Na Uy và Cơ quan phát triển Chính phủ Úc. lâm kết hợp
Nghiên cứu này được tiến hành và là một phần trong Chương trình nghiên cứu của CGIAR về Rừng, Cây và Nông lâm kết hợp. Chương trình hợp tác này hướng tới nâng cao việc quản lý và sử dụng rừng, nông lâm và nguồn giống cây trồng tại các cánh rừng và khu vực đất nông nghiệp. Tổ chức Nghiên cứu Lâm nghiệp Quốc tế (CIFOR) đi đầu trong chương trình hợp tác này cùng với sự phối hợp với Bioversity International, CIRAD, Trung tâm Nông nghiệp Nhiệt đới quốc tế và Trung tâm Nghiên cứu Nông Lâm Thế giới.

\section{USAID}
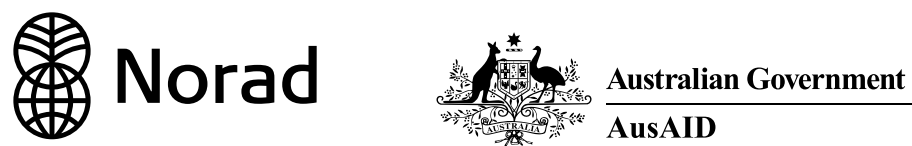

Tổ chức Nghiên cứu Lâm nghiệp Quốc tế CIFOR thúc đẳy sự phồn vinh cho nhân loại, bảo vệ môi trường và bình đẳng thông qua việc triển khai các hoạt động nghiên cứu nhằm cung cấp thông tin về chính sách và các phương thức hoạt động ảnh hưởng đến rừng ở các nước đang phát triển. CIFOR là một trong 15 trung tâm trực thuộc Nhóm Tứ vấn Nghiên cứu Nông nghiệp Quốc tế (CGIAR). Trụ sở chính của chúng tôi đóng tại Bogor (Indonesia) và các văn phòng tại châu Á, châu Phi và Nam Mỹ. 